\title{
Safety and efficacy of endovascular treatment for carotid artery stenoses using proximal protection systems: 30 -day follow-up
}

\author{
Pawel Latacz', Marian Simka ${ }^{2}$, Marek Kazibudzki ${ }^{3}$, Pawel Brzegowy ${ }^{4}$, Jan J. Kesik ${ }^{5}$ \\ 'Department of Vascular Surgery, University Hospital in Krakow, Poland \\ ${ }^{2}$ Private Healthcare Institution SANA Outpatient Department of Angiology, Pszczyna, Poland \\ ${ }^{3}$ Department of Vascular Surgery, John Paul II Hospital in Krakow, Poland \\ ${ }^{4}$ Chair of Radiology, Jagiellonian University Collegium Medicum, Krakow, Poland \\ ${ }^{5}$ Department of Vascular Surgery and Angiology, Medical University of Lublin, Poland
}

\begin{abstract}
Introduction. Although surgical endarterectomy remains the treatment of choice for carotid artery stenosis, carotid artery stenting (CAS) with use of proximal protection systems (PPS) plays an important role as alternative treatment modality, especially in high risk patients.

This study was aimed at the assessment of safety of CAS with use of the PPS and also at identification of risk factors associated with this procedure.

Material and methods. This was a post hoc analysis, with 30-day follow-up. We analysed results of treatment of 94 patients who underwent 97 CAS with PPS, 47 such procedures in asymptomatic, and 50 in symptomatic individuals.
\end{abstract}

Results. There were 0 strokes during 30-day follow-up. Transient ischaemic attacks occurred in 2 patients (2\%) in symptomatic group. Risk factors of these adverse events comprised: tortuosity of the managed artery, chronic obstructive pulmonary disease, long lesion of the internal carotid artery and history of myocardial infarction.

Conclusions. CAS with the use of PPS seems to be a relatively very safe procedure in high risk patients.

Key words: carotid angioplasty, proximal protection systems, stents

Acta Angiol 20I7; 23, I: I-8

\section{Introduction}

Carotid artery angioplasty with stenting (CAS) is increasingly playing a role as alternative for surgical endarterectomy (CEA) in high risk patients, and also in those patients who present with other, non-stenotic lesions of the carotid arteries [1-4]. Most of published papers on CAS deal with distal protection systems (DPS) [5-9]. Still, it is believed that proximal protection systems (PPS) in terms of their safety and efficacy have potential advantage over distal ones, yet evidence of such superiority remains to be documented [10-13].
This post hoc survey, with 30-day follow-up, was aimed at the assessment of safety and efficacy of CAS with the use of PPS for the treatment of internal carotid artery (ICA) stenosis and at identification of risk factors associated with this procedure.

\section{Material and methods}

We analysed results of the treatment with the use of PPS in 94 consecutive patients ( 34 women and 60 men) who were managed by our team at departments of vascular surgery from March 20II to December 20 I 5. 
Table I. Demographic and clinical characteristics of the patients; number of patients: $N=94$

\begin{tabular}{|l|c|c|}
\hline Patients' characteristics & \multicolumn{2}{c|}{$69.5( \pm 8.05)$} \\
\hline Age \pm SD & 6 & 5 \\
\hline Matients older than 80 year & $60 / 34$ & $63 / 37$ \\
\hline Asymptomatic patients & 42 & 42 \\
\hline Risk factors & \multicolumn{2}{|l|}{} \\
\hline Stable coronary heart disease & 33 & 35 \\
\hline Arterial hypertension & 86 & 91 \\
\hline Diabetes mellitus type 2 & 28 & 30 \\
\hline Dislipidemia & 56 & 60 \\
\hline Cigarette smoking & 24 & 26 \\
\hline Renal impairment & 6 & 6 \\
\hline Peripheral artery disease & 6 & 6 \\
\hline History of percutaneous coronary angioplasty & 9 & 10 \\
\hline History of coronary artery bypass graft surgery & 2 & 2 \\
\hline History of cancer & 0 & 0 \\
\hline History of myocardial infarction & 20 & 21 \\
\hline Symptomatic carotid artery stenosis & 55 & \\
\hline History of transient ischemic attack & 26 & 56 \\
\hline History of stroke & 29 & 28 \\
\hline Bilateral stenosis of the internal carotid artery & 33 & 31 \\
\hline Occlusion of the internal carotid artery & 5 & 35 \\
\hline Stenosis of the vertebral artery & 4 & 5 \\
\hline
\end{tabular}

Table 2. Risks factors in asymptomatic vs. symptomatic patients

\begin{tabular}{|c|c|c|c|}
\hline Risk factor & $\begin{array}{l}\text { Asymptomatic patients } \\
\text { (47 procedures) }\end{array}$ & $\begin{array}{l}\text { Symptomatic patients } \\
\text { (50 procedures) }\end{array}$ & $P$ value \\
\hline Mean age $( \pm S D)$ & $68.4 \pm 8.7$ & $70.7 \pm 7.19$ & NS \\
\hline Patients aged $>80$ years & 2 & 4 & NS \\
\hline Patients aged $<60$ years & 7 & 4 & NS \\
\hline Male patients & 27 & 34 & NS \\
\hline Stable coronary heart disease & 19 & 14 & $<0.05$ \\
\hline Congestive heart failure & 3 & 5 & NS \\
\hline Cigarette smoking & 13 & 11 & NS \\
\hline Diabetes mellitus type 2 & 9 & 19 & $<0.05$ \\
\hline Arterial hypertension & 36 & 50 & NS \\
\hline Dislipidemia & 27 & 29 & NS \\
\hline Renal impairment & 3 & 3 & NS \\
\hline Chronic obstructive pulmonary disease & 2 & 3 & NS \\
\hline Peripheral arterial disease & 3 & 3 & NS \\
\hline History of myocardial infarction & 8 & 12 & NS \\
\hline History of percutaneous coronary angioplasty & 3 & 6 & NS \\
\hline History of coronary artery bypass graft surgery & $\mathrm{I}$ & $\mathrm{I}$ & NS \\
\hline Aortic or mitral valve disease & 0 & 0 & NS \\
\hline Contralateral stenosis of the internal carotid artery & 14 & 19 & 0.06 \\
\hline Occlusion of the internal carotid artery & 2 & 3 & NS \\
\hline Stenosis of the vertebral artery & 4 & I & NS \\
\hline
\end{tabular}

NS - difference statistically not significant

Patients were aged $69 \pm 8.1$ years, 6 patients $(5 \%)$ were aged more than 80 years. A total of 97 endovascular treatments with stent implantation have been performed, 47 such procedures in asymptomatic patients, and 50 stentings in symptomatic patients. Some patients underwent endovascular treatment more than once. A demographic and clinical characteristic of patients, including potential risk factors, is given in Table I, and comparison between asymptomatic and symptomatic patients regarding these risk factors is presented in Table 2. Localisation of the lesions managed with stent implantation is given in Table 3 . 
Table 3. Location of the lesions treated $(\mathrm{N}=97)$

\begin{tabular}{|l|c|c|}
\hline Artery & N & $\%$ \\
\hline Left internal carotid artery & 48 & 49 \\
\hline Right internal carotid artery & 49 & $5 \mathrm{I}$ \\
\hline Left vertebral artery & 4 & 4 \\
\hline Right vertebral artery & I & I \\
\hline
\end{tabular}

Inclusion criteria for endovascular angioplasty with stent implantation comprised: more than $65 \%$ stenosis of the ICA in symptomatic patients and more than $80 \%$ stenosis of the ICA in asymptomatic patients. Main indication for the use of PSP instead of another type of protection included: presence of unstable symptomatic lesions, critically narrowed ICA, tortuosity of the artery, presence of thrombi in the lesion, technical problems with the use of a DPS.

Exclusion criteria for stenting procedure comprised: highly calcified lesions, no adequate vascular access, contraindications for antiplatelet therapy and a lack of patient's consent. Symptomatic patients were managed at least 5 days after neurologic event, preferentially on the $7^{\text {th }}-10^{\text {th }}$ day, depending on the findings of MRI of the brain and appearance of cerebral lesions revealed by this test; this was in line with recommendations coming from published studies [10, 12].

Two types of PPS were utilised: the Mo.Ma (Medtronic, Minneapolis, MN, USA) and the Gore
Flow Reversal System (Gore \& Associates, Inc., Flagstaff, AZ, USA). The first system protects the brain against embolisation thanks to stopped flow in the ICA, which occurs after the balloons of this system are expanded in the common and external carotid arteries (Fig. IA). In the case of the Gore Flow system, there is a flow reversal in the ICA, which results from temporary shunting from the ICA to the femoral vein through catheters and filter of this device (Fig. IB). Mean time of closure of the common carotid artery was $422 \mathrm{~s}$ ( $\pm 178 \mathrm{~s}$ ); the shortest closure time was $150 \mathrm{~s}$. Characteristics of the types of PPS, stents utilised in our patients and presence of embolic material secured by protection systems are given in Table 4.

Standard preprocedural management of patients comprised multidisciplinary assessment, including neurological, vascular and cardiologic consultations. Potential risks and benefits associated with the planned procedure were discussed with the patients, and all patients gave their written informed consent. Neurological assessment was performed at least before the procedure and on the first postprocedural day. Sonographic follow-up of the treated arteries was performed on the day of procedure, and then after I and 6 months.

All patients completed the 30-day follow-up, which was primarily aimed at the assessment of safety of these endovascular procedures. Patients were advised to report any neurological events that occurred during this period. Neurological symptoms were categorized
A

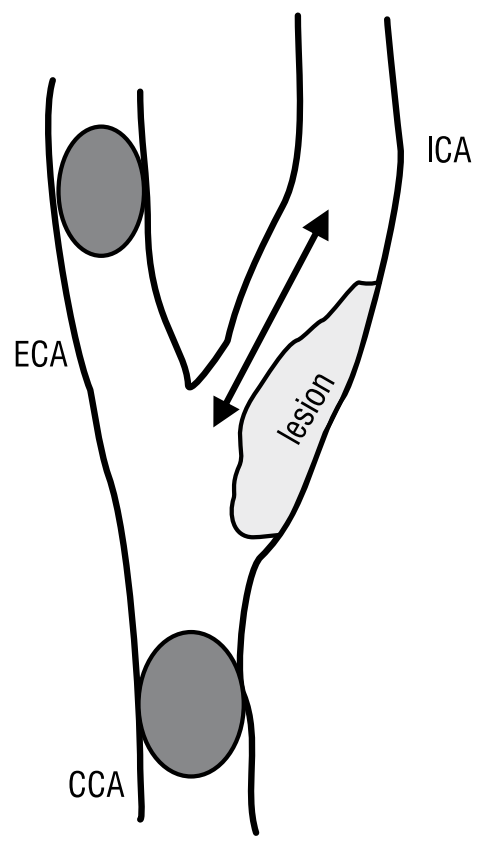

B

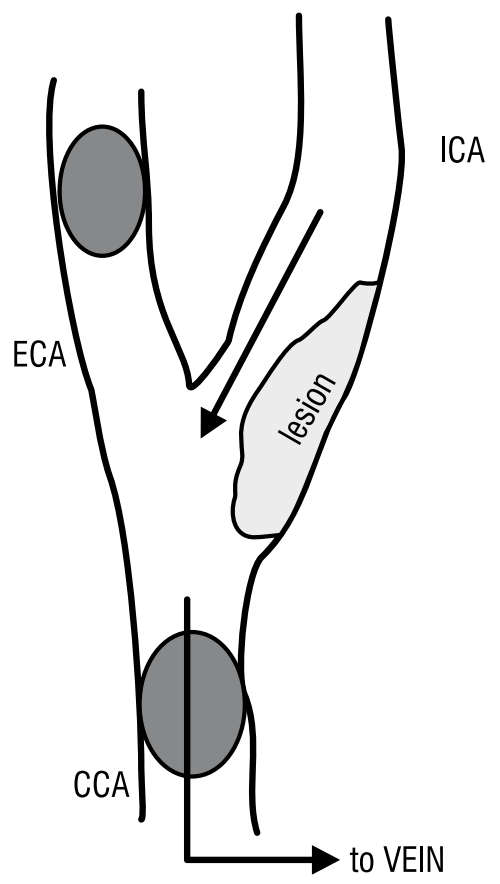

Figure IA. Scheme of Mo.Ma system - blockage flow in ICA during inflation of balloon in CCA and ECA; B. Scheme of Gore Flow Reversal System - there is a flow reversal in the ICA, which results from temporary shunting from the ICA to the femoral vein through catheters and filter of this device during inflation of balloon in ECA and CCA. CCA - common carotid artery; ECA - external carotid artery; ICA — internal carotid artery 
Table 4. Characteristics of protection systems and stents utilized in 408 procedures in asymptomatic vs. symptomatic patients

\begin{tabular}{|c|c|c|c|}
\hline & $\begin{array}{l}\text { Asymptomatic patients } \\
\text { (47 procedures) }\end{array}$ & $\begin{array}{l}\text { Symptomatic patients } \\
\text { ( } 50 \text { procedures) }\end{array}$ & p value \\
\hline \multicolumn{4}{|l|}{ Protection systems } \\
\hline Proximal protection systems & 40 & 57 & NS \\
\hline Mo.Ma (Medtronic, Minneapolis, MN, USA) & 36 & 50 & NS \\
\hline $\begin{array}{l}\text { Gore Flow Reversal System (Gore \& Associates, Inc., Flagstaff, } \\
\text { AZ, USA) }\end{array}$ & 4 & 7 & NS \\
\hline \multicolumn{4}{|l|}{ Stents } \\
\hline Precise (Cordis, Fremont, CA, USA) & 8 & 21 & 0.05 \\
\hline Carotid Wallstent (Boston Scientific, Natick, MA, USA) & 16 & 23 & 0.05 \\
\hline Cristallo Ideale (Medtronic, Minneapolis, MN, USA) & 16 & 13 & NS \\
\hline Close-cell design stents & 32 & 36 & NS \\
\hline Open-cell stents & 8 & 21 & 0.05 \\
\hline \multicolumn{4}{|l|}{ Macroscopically visible embolic material in protection system } \\
\hline Single plaque or thrombus & 16 & 25 & 0.05 \\
\hline A little of debris & 0 & 3 & NS \\
\hline A lot of debris & 3 & 3 & NS \\
\hline
\end{tabular}

NS - difference statistically not significant

as follows: transient ischaemic attack, which was defined as an acute neurological deficit resulting from focal temporary cerebral or retinal ischaemia that lasted less than 24 hours; stroke, which was defined as a new cerebrovascular event of ischaemic or haemorrhagic aetiology resulting in cerebral infarction and neurological deficit. Strokes were further classified as: minor - with neurological deficits lasting less than 30 days, or lasting longer than 30 days but presenting with small deficit (National Institute of Health Stroke Scale up to 4 points); major - with neurological deficits lasting longer than 30 days; and fatal - a stroke (ischaemic or haemorrhagic) resulting in death.

The primary endpoint was the proportion of patients who had stroke or stroke-related death. We included all types of strokes, both ipsi- and contralateral, as well as minor, major and fatal strokes.

The secondary endpoint was the proportion of patients who had myocardial infarction (both STEMI and non-STEMI events) or a death that was not caused by stroke. In addition to demographic and clinical data of the patients, we analysed angiographic characteristics, such as presence of coexisting lesions in other arteries supplying the brain, including intracranial stenoses. Also, we assessed endovascular technique used (type of protection, type of stent, duration of the procedure, duration of occlusion of an artery, etc.).

\section{Statistical analysis}

Continuous variables were expressed as means \pm standard deviation; categorical variables were expressed as percentages. Analysis of normality was performed with the Kolmogorov-Smirnov test. Comparison of categorical variables between the groups was performed using the chi-square test. Comparisons of continuous variables between the two groups were performed using the independent sample $t$-test. Multivariate, stepwise backward conditional logistic regression analysis was used to determine independent predictors of successful intervention. All significant parameters in the univariate analysis were selected in the multivariate model. The significance of the two-tailed $p$ was set at $\mathrm{p}<0.05$. Statistical analysis was performed using the SPSS software (Statistical Package for the Social Sciences (version 23.0, SPSS Inc., Chicago, IL, USA).

\section{Results}

Complications associated with the treatment are presented in Table 5. There was neither a fatality nor a stroke during 30-day follow-up. Transient ischaemic

Table 5. Complications in asymptomatic vs. symptomatic patients

\begin{tabular}{l|c|c|c|}
\hline $\begin{array}{l}\text { Complications during } \\
\text { 30-day follow up }\end{array}$ & $\begin{array}{c}\text { Asymptoma- } \\
\text { tic patients } \\
\text { (47 proce- } \\
\text { dures) }\end{array}$ & $\begin{array}{c}\text { Symptoma- } \\
\text { tic patients } \\
\text { (50 proce- } \\
\text { dures) }\end{array}$ \\
\hline Stroke & 0 & 0 & NS \\
\hline $\begin{array}{l}\text { Transient ischemic } \\
\text { attack }\end{array}$ & 0 & 2 & NS \\
\hline $\begin{array}{l}\text { Hyperperfusion syn- } \\
\text { drome }\end{array}$ & $\mathrm{I}$ & 0 & NS \\
\hline $\begin{array}{l}\text { Other serious neuro- } \\
\text { logical events }\end{array}$ & 0 & 0 & NS \\
\hline $\begin{array}{l}\text { Myocardial infarction } \\
\text { All fatalities during } \\
\text { 30-day follow up }\end{array}$ & 0 & 0 & NS \\
\hline
\end{tabular}

NS — difference statistically not significant 
Table 6. Risk factors associated with postprocedural complications (TIA, intolerance of protection system) revealed by logistic multivariate analysis

\begin{tabular}{l|c|c|}
\hline $\begin{array}{l}\text { All patients (97 procedures) } \\
\text { Risk factor }\end{array}$ & $\begin{array}{l}\text { Hazard } \\
\text { ratio }\end{array}$ & p value \\
\hline Tortuosity of the managed artery & 12.15 & 0.002 \\
\hline Chronic obstructive pulmonary disease & 7.36 & 0.007 \\
\hline $\begin{array}{l}\text { Long lesion of the internal carotid } \\
\text { artery }\end{array}$ & 7.36 & 0.007 \\
\hline History of myocardial infarction & 4.42 & 0.03 \\
\hline
\end{tabular}

attacks (TIA), which resolved within 6 hours, occurred in 2 patients $(2.1 \%)$. These patients had a history of previous TIAs. There was one case (I.0\%) of postprocedural hyperperfusion syndrome. This patient, who presented with bilateral critical stenosis of the ICAs, developed this syndrome 10 hours after successful revascularization of the left ICA. Conservative management resulted in complete resolution of neurological symptoms. After one month this patient underwent successful revascularization of the contralateral ICA. Five patients (5.1\%) developed neurological symptoms after introduction of the PPS, majority of these patients presented with contralateral carotid lesions. Still, there were no clinical consequences associated with this intolerance. Complication rates did not differ significantly between symptomatic and asymptomatic patients.

During or after the procedure 3 asymptomatic (6.4\%) and 2 symptomatic patients ( $4.0 \%$ ) developed hypotension, which required an intravenous administration of dopamine, yet did not result in further clinical sequelae. Logistic multivariate analysis revealed several risk factors predisposing for peri- and postprocedural neurological complications, namely: TIA or intolerance of the protection system. These comprised: tortuosity of the managed artery, presence of long lesions in the internal carotid arteries, a history of chronic obstructive pulmonary disease or myocardial infarction. Details are given in Table 6.

\section{Discussion}

Incidence of major adverse events in our material $(0 \%)$ was much lower than recommended in the guidelines (3\% for asymptomatic and $6 \%$ for symptomatic patients). Still, there are some limitations of our study. Firstly, it was a retrospective analysis and patients were not randomly allocated into PPS or DPS arms, thus a potential selection bias could occur. The same applies to the selection of stents, which were tailored according to the characteristics and anatomy of lesions. Also, this survey analysed adverse events during a 30-day follow-up, when perhaps a longer observation will be justified.
In our patients neurological adverse events (only: TIA and intolerance of protection system, since there were no strokes) were associated with several risk factors: tortuosity of the managed artery, long lesions in the ICA, history of chronic obstructive pulmonary disease and history of myocardial infarction. Other researchers found that complications were associated with bilateral carotid disease, long lesions, advanced patient's age and a history of myocardial infarction [10, II, 13-16]. Data revealed by large-scale registries on endovascular carotid interventions suggest that because of a risk of cerebral embolisation, the use of protection system during CAS is warranted $[10,11,17,18]$. Indeed, in our patients very often there was quite a lot of embolic material filtered by protection system (Table 4).

For the time being CAS procedures are primarily performed with the use of a (DPS) [5-9]. Prevalence of ischaemic cerebral events during 30-day follow-up reported by randomised trials, with different types of DSP utilised, was at the level of $4 \%$ in asymptomatic patients, and even as high as $10 \%$ in symptomatic individuals [5-9]. By contrast, open-label studies when also a proximal protection has been applied (such a system was used in approximately $30 \%$ of procedures) reported much lower rates of adverse events: $0.9-2.4 \%$ of death or stroke [10-13]. There is a growing body of evidence supporting the use of PPS during CAS. Regarding the Mo.Ma system, there are some already published studies $[12,19,20]$. In the randomized multicentre ARMOUR study, which evaluated a group of 222 patients (15\% of them were symptomatic, $29 \%$ were older than 80 years; occlusion or stenosis of the contralateral artery constituted an exclusion criterion for the use of PPS) the composite complication rate (comprising: stroke, death and myocardial infarction) was $2.7 \%$, and stroke rate during 30 days was $0.9 \%$ [ 12$]$. In the study published by Stabile et al. the Mo.Ma system was used in I,300 patients. The composite complication rate (comprising: stroke and death) at 30 -day follow-up was $1.4 \%$ (3\% in symptomatic patients and $0.9 \%$ in asymptomatic ones). It was not increased in elderly patients. Low operator experience (less than 100 procedures performed) was associated with a higher risk of adverse events [19]. In 2014 Khripun et al. published the results of an open-label study with the use of the Mo.Ma system. Incidence of complications during 30-day follow-up in this survey was $0.6 \%$ [20].

Efficacy and safety of the Gore Flow Reversal System have been evaluated in the multicentre prospective, nonrandomized EMPiRE study [2I]. In this study 245 patients have been studied, including $30 \%$ symptomatic and $16 \%$ older than 80 years. In this study contralateral stenosis or occlusion was not an exclusion criterion (actually, $10.5 \%$ of patients enrolled presented with 
an occlusion of the contralateral ICA). Composite complication rate (including: stroke, death, myocardial infarction or TIA) during 30-day follow-up was $4.5 \%$. Composite complication rate comprising only stroke and death was $2.9 \%$ (still, not a single patient in this study developed major stroke). The death/stroke rates in this study in the symptomatic, asymptomatic, and patients older than 80 years were $2.6 \%, 3 \%$, and $2.6 \%$, respectively $[21]$. Another study on the use of the Gore Flow Reversal System, which was published in 2012 by Nikas et al., revealed complication rate (comprising: stroke, death and myocardial infarction) at the level of $1.6 \%$ [22].

Similarly, clinical benefit associated with the use of a PPS has been demonstrated by cerebral diffusion MR studies. Bijuklic et al., who compared distal and proximal protection systems studying postprocedural cerebral lesions by means of diffusion MR imaging, found that there were significantly fewer new lesions (45.2\% vs. $87.1 \% ; p=0.001$ ) if the PPS were used [23]. Montoresi et al. [24] demonstrated that there were fewer periprocedural embolic events with the use of the Mo.Ma system if compared to a DPS: the FilterWire. Meta-analysis by Bersin et al. [25], which was published in 2012 and discussed results of CAS with the use of PPS in 2397 patients, reported $1.71 \%$ stroke rate during 30 -day follow-up and $2.6 \%$ incidence of stroke, death or myocardial infarction. In this meta-analysis diabetes mellitus and advanced patient's age were found to be associated with increased risk of adverse events.

All the above-citied data are in line with our results. There were neither fatalities nor strokes in our patients, and the only major adverse events comprised two TIAs that completely resolved within few hours, without further neurological sequelae. Although an introduction of PPS into the ICA can be technically challenging and there were many patients with contralateral carotid disease (about $40 \%$ of our patients presented with significant, at least $70 \%$, stenosis of contralateral ICA, and about $5 \%$ of patients had completely occluded contralateral artery), only $5.1 \%$ of patients developed neurological symptoms after introduction of PPS and there were no clinical consequences related to this intolerance. By contrast, in the AROMOUR study, which did not enrol patients with significant contralateral carotid lesions, there was an intolerance of protection system in $13.8 \%$ of patients and $0.9 \%$ stroke rate [ 12$]$. Low incidence of neurological adverse events associated with the use of PPS by our team can partially be explained by some modifications of endovascular technique used. In each patient we tried to postpone the closure of the common carotid artery until the guidewire and stent were introduced into the distal part of the system. In selected cases (there were 2 such patients) we utilised both proximal and distal protections. Such a dual protection has already been shown to be safe and effective $[22,26]$. Also, we applied lesion-tailored stents: preferentially closed-cell stents, but in selected patients who presented with tortuous arteries we implanted stents with an open-cell design (such as the Precise stent/Cordis, Fremont, CA, USA). Although we did not observe different clinical outcomes in patients managed with closed- and open-cell stents, other researchers revealed better results after implantation of closed-cell stents [27]. Still, for technical reasons, such stents cannot be used in every case. Recently, a new generation of carotid stents has been marketed; these stents combine small area of the cells with flexibility characteristic for open-cell devices. Perhaps, such stents, which appear to be an interesting alternative for currently utilised ones, will further improve results of carotid stenting $[27,28]$.

Whilst our study is not definitive and therefore cannot guide the treatment, nonetheless we have found that in patients presenting with tortuosity of the managed artery, presence of long lesions in the internal carotid arteries, a history of chronic obstructive pulmonary disease or myocardial infarction, periprocedural adverse events were more likely that in patients without these risk factors. Thus, perhaps in individuals presenting with these comorbidities an alternative treatment modality should be considered, either surgical endarterectomy, carotid stenting with the use of distal protection, or pharmacological treatment.

\section{Conclusions}

We can conclude that CAS with the use of a PPS is a relatively safe endovascular procedure, with a potential benefit over DPS. We suggest that proximal protection devices should be used whenever technically feasible, still in patients presenting with risk factors of periprocedural adverse event, such as tortuosity of the managed artery, presence of long lesions in the internal carotid arteries, a history of chronic obstructive pulmonary disease or myocardial infarction, an alternative treatment modality should be considered. Future strategy treatment for carotid artery stenosis should be based on an individual approach.

\section{References}

I. Endarterectomy for asymptomatic carotid artery stenosis. Executive Committee for the Asymptomatic Carotid Atherosclerosis Study. JAMA. 1995; 273(18): 1421-1428, indexed in Pubmed: 7723155 .

2. Barnett HJ, Taylor DW, Eliasziw M, et al. Benefit of carotid endarterectomy in patients with symptomatic moderate or severe stenosis. North American Symptomatic Carotid Endar- 
terectomy Trial Collaborators. N Engl J Med. 1998; 339(20): 1415-1425, doi: 10.1056/NEJM19981| 123392002, indexed in Pubmed: 9811916.

3. North American Symptomatic Carotid Endarterectomy Trial Collaborators. Beneficial effect of carotid endarterectomy in symptomatic patients with high-grade carotid stenosis. N Engl J Med. 1991; 325(7): 445-453, doi: 10.1056/ NEJM19910815325070I, indexed in Pubmed: 1852179.

4. Randomised trial of endarterectomy for recently symptomatic carotid stenosis: final results of the MRC European Carotid Surgery Trial (ECST). Lancet. 1998; 35I(9113): 1379-1387, indexed in Pubmed: 9593407.

5. Hobson RW, Howard VJ, Roubin GS, et al. CREST Investigators. Carotid artery stenting is associated with increased complications in octogenarians: 30-day stroke and death rates in the CREST lead-in phase. J Vasc Surg. 2004; 40(6): II06-IIII, doi: 10.1016/j.jvs.2004.10.022, indexed in Pubmed: 15622363.

6. Mas JL, Chatellier G, Beyssen B, et al. Endarterectomy versus stenting in patients with symptomatic severe carotid stenosis. N Engl J Med. 2006; 355(16): 1660-1671, doi: 10.1056/nejmoa061752.

7. Wimmer NJ, Yeh RW, Cutlip DE, et al. Risk prediction for adverse events after carotid artery stenting in higher surgical risk patients. Stroke. 2012; 43(I2): 3218-3224, doi: 10.1161/ STROKEAHA. I 12.673194, indexed in Pubmed: 23127975.

8. Bangalore S, Kumar S, Wetterslev J, et al. Carotid artery stenting vs carotid endarterectomy: meta-analysis and diversity-adjusted trial sequential analysis of randomized trials. Arch Neurol. 201 I; 68(2): 172-184, doi: 10.1001/archneurol.2010.262, indexed in Pubmed: 20937941.

9. Massop D, Dave R, Metzger C, et al. SAPPHIRE Worldwide Investigators. Stenting and angioplasty with protection in patients at high-risk for endarterectomy: SAPPHIRE Worldwide Registry first 2,00I patients. Catheter Cardiovasc Interv. 2009; 73(2): 129-136, doi: 10.1002/ccd.21844, indexed in Pubmed: 18924164.

10. Cremonesi A, Gieowarsingh S, Spagnolo B, et al. Safety, efficacy and long-term durability of endovascular therapy for carotid artery disease: the tailored-Carotid Artery Stenting Experience of a single high-volume centre (tailored-CASE Registry). Eurolntervention. 2009; 5(5): 589-598, indexed in Pubmed: 20142180.

II. Pieniazek P, Musialek P, Kablak-Ziembicka A, et al. Carotid artery stenting with patient- and lesion-tailored selection of the neuroprotection system and stent type: early and 5 -year results from a prospective academic registry of 535 consecutive procedures (TARGET-CAS). J Endovasc Ther. 2008; 15(3): 249-262, doi: 10.1583/07-2264.1, indexed in Pubmed: 18540694.

12. Ansel GM, Hopkins LN, Jaff MR, et al. Investigators for the ARMOUR Pivotal Trial. Safety and effectiveness of the INVATEC MO.MA proximal cerebral protection device during carotid artery stenting: results from the ARMOUR pivotal trial. Catheter Cardiovasc Interv. 2010; 76(I): 1-8, doi: 10.1002/ccd.22439, indexed in Pubmed: 20222019.

13. Pieniążek P, Tekieli L, Musiałek P, et al. Carotid artery stenting according to the tailored-CAS algorithm is associated with a low complication rate at 30 days: data from the TARGET-CAS study. Kardiol Pol. 2012; 70(4): 378-386.

14. White RA, Sicard GA, Zwolak RM, et al. SVS Outcomes Committee. Society of vascular surgery vascular registry compari- son of carotid artery stenting outcomes for atherosclerotic vs nonatherosclerotic carotid artery disease. J Vasc Surg. 2010; 5I(5): III6-I I23, doi: 10.1016/i.jvs.2009.11.082, indexed in Pubmed: $2034755 \mathrm{I}$.

15. Doig D, Turner EL, Dobson J, et al. Predictors of stroke, myocardial infarction or death within 30 days of carotid artery stenting: results from the International Carotid Stenting Study. Eur J Vasc Endovasc Surg. 2016; 5 I (3): 327-334, doi: 10.1016/i. ejvs.2015.08.013.

16. Khan M, Qureshi Al. Factors associated with increased rates of post-procedural stroke or death following carotid artery stent placement: a systematic review. J Vasc Interv Neurol. 2014; $7(1):$ II -20.

17. Pandey AS, Koebbe CJ, Liebman K, et al. Low incidence of symptomatic strokes after carotid stenting without embolization protection devices for extracranial carotid stenosis: a single-institution retrospective review. Neurosurgery. 2008; 63(5): 867 72; discussion 872, doi: 10.1227/0I.NEU.0000327886.32379. D0, indexed in Pubmed: 19005376.

18. Reimers B, Schlüter M, Castriota F, et al. Routine use of cerebral protection during carotid artery stenting: results of a multicenter registry of 753 patients. Am J Med. 2004; I 16(4): 217-222, doi: 10.1016/j.amjmed.2003.09.043, indexed in Pubmed: 14969648.

19. Stabile E, Salemme L, Sorropago G, et al. Proximal endovascular occlusion for carotid artery stenting: results from a prospective registry of 1,300 patients. J Am Coll Cardiol. 2010; 55(16): 166I-1667, doi: 10.1016/j.jacc.2009.11.079, indexed in Pubmed: 20394868.

20. Diuzhikov AA, Khripun AV, Malevannyı̆ MV, et al. Immediate and remote results of using carotid endarterectomy and stenting of internal carotid arteries. Angiol Sosud Khir. 2013; 19(2): 102-1 10.

21. Clair DG, Hopkins LN, Mehta M, et al. EMPiRE Clinical Study Investigators. Neuroprotection during carotid artery stenting using the GORE flow reversal system: 30-day outcomes in the EMPiRE Clinical Study. Catheter Cardiovasc Interv. 201 I; 77(3): 420-429, doi: $10.1002 / \mathrm{ccd} .22789$, indexed in Pubmed: 20853365.

22. Nikas D, Reith W, Schmidt A, et al. Prospective, multicenter European study of the GORE flow reversal system for providing neuroprotection during carotid artery stenting. Catheter Cardiovasc Interv. 2012; 80(7): 1060-1068, doi: 10.1002/ccd.24402, indexed in Pubmed: 22644906.

23. Bijuklic K, Wandler A, Hazizi F, et al. The PROFI study (Prevention of Cerebral Embolization by Proximal Balloon Occlusion Compared to Filter Protection During Carotid Artery Stenting): a prospective randomized trial. J Am Coll Cardiol. 2012; 59(15): 1383-1389, doi: 10.1016/j.jacc.2011.11.035, indexed in Pubmed: 22284330.

24. Montorsi P, Caputi L, Galli S, et al. Microembolization during carotid artery stenting in patients with high-risk, lipid-rich plaque. A randomized trial of proximal versus distal cerebral protection. J Am Coll Cardiol. 201 I; 58(16): 1656-1663, doi: 10.1016/i. jacc.2011.07.015, indexed in Pubmed: 21982309.

25. Bersin RM, Stabile E, Ansel GM, et al. A meta-analysis of proximal occlusion device outcomes in carotid artery stenting. Catheter Cardiovasc Interv. 2012; 80(7): 1072-1078, doi: 10.1002/ $\underline{\text { ccd.24433, indexed in Pubmed: } 22454248 .}$. 
26. Latacz P, Ochała A, Janas P, et al. Composed angioplasty of the multilevel right common and internal carotid artery stenoses with implantation stents with used of proximal and distal protection system. Kardiol Pol. 2012; 70(I): 88-90.

27. Kouvelos GN, Patelis N, Antoniou GA, et al. Meta-analysis of the Effect of Stent Design on 30-Day Outcome After Carotid Artery Stenting. J Endovasc Ther. 2015; 22(5): 789-797, doi: 10.1177/15266028/5598753, indexed in Pubmed: 26232399 .

28. Setacci C, Speziale F, De Donato G, et al. IRON-Guard Study Group. Physician-initiated prospective Italian Registry of carotid stenting with the C-Guard mesh-stent: the IRON-Guard registry. Rationale and design. J Cardiovasc Surg (Torino). 2015; 56(5): 787-791, indexed in Pubmed: 25996843.

29. Kajihara Y, Sakamoto S, Kiura Y, et al. Comparison of dual protection and distal filter protection as a distal embolic protection method during carotid artery stenting: a single-center carotid artery stenting experience. Neurosurg Rev. 2015; 38(4):
67|-676, doi: $10.1007 / \mathrm{s} 10143-0 \mid 5-0639-x$, indexed in Pubmed: 25953614 .

30. Hopf-Jensen S, Marques L, Preiß M, et al. Initial clinical experience with the micromesh Roadsaver carotid artery stent for the treatment of patients with symptomatic carotid artery disease. J Endovasc Ther. 2015; 22(2): 220-225, doi: $10.1177 / 1526602815576337$, indexed in Pubmed: 25809366 .

31. Eckstein HH, Ringleb P, Allenberg JR, et al. Results of the Stent-Protected Angioplasty versus Carotid Endarterectomy (SPACE) study to treat symptomatic stenoses at 2 years: a multinational, prospective, randomised trial. Lancet Neurol. 2008; 7(10): 893-902, doi: 10.1016/S1474-4422(08)70196-0, indexed in Pubmed: 18774746.

32. lelasi A, Latib A, Godino C, et al. Clinical outcomes following protected carotid artery stenting in symptomatic and asymptomatic patients. J Endovasc Ther. 2010; 17(3): 298-307, doi: 10.1583/09-2997.1. 